\title{
Indigo carmine chromoendoscopic appearances of enteropathy-associated T-cell lymphoma during double-balloon endoscopy in a patient with celiac disease
}
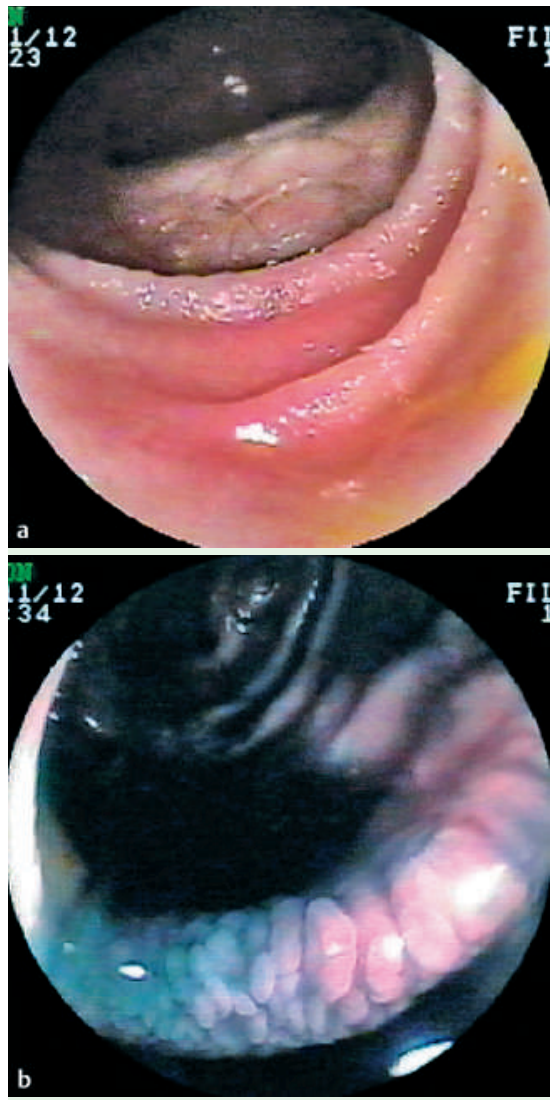

Figure 1 Endoscopic views of scalloped jejunal folds in a patient with celiac disease before dye staining (a) and after spraying with $0.1 \%$ indigo carmine solution (b).

Patients with celiac disease have a 28fold increased risk of developing enteropathy-associated T-cell lymphoma compared with the general population [1]. Early diagnosis is therefore required to improve their prospects. Indigo carmine chromoendoscopy highlights mucosal irregularities and improves the detection of malignant lesions [2]. Furthermore, it can delineate villous atrophy in celiac disease [3]. This method is commonly used in upper and lower gastrointestinal endoscopy but this is not yet the case in small-intestinal endoscopy. In this report we describe the chromoendoscopic appearances of jejunal enteropathy-associated T-cell lymphoma, before and after
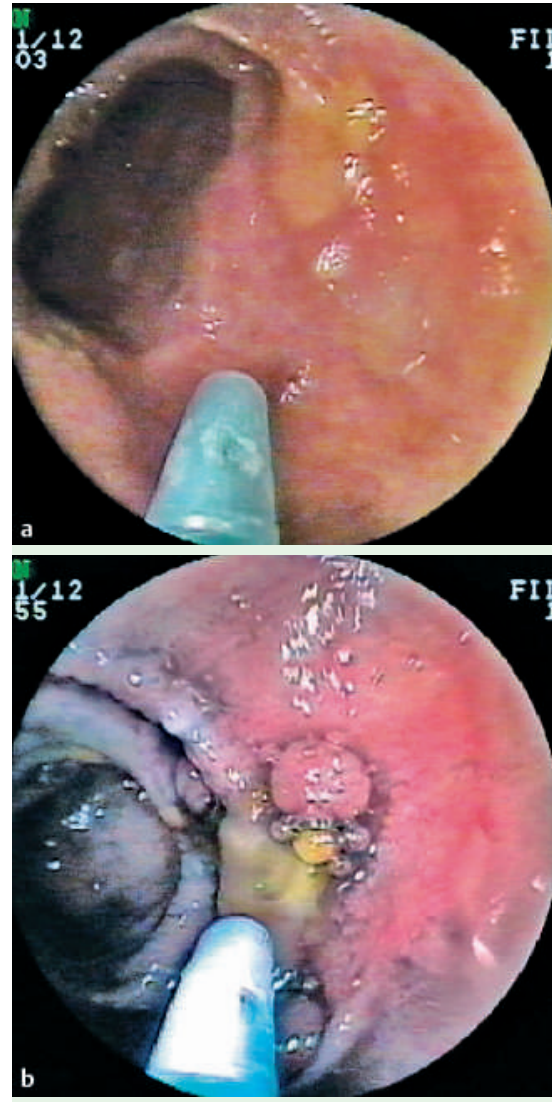

Figure 2 Endoscopic views of a round jejuna ulcer in a patient with celiac disease and enteropathy-associated T-cell lymphoma before dye staining (a) and after spraying with $0.1 \%$ indigo carmine solution (b).

indigo carmine spraying, in a patient who was undergoing a double-balloon endoscopy procedure.

A 68-year-old Caucasian woman with celiac disease who had been on a glutenfree diet for 3 years was referred for double-balloon endoscopy because an abdominal computed tomography scan had shown thickened small-intestinal wall. Endoscopy was performed with a double-balloon endoscopy system (FMH Medical Inc., Veenendaal, The Netherlands). Using a catheter, $10 \mathrm{~mL}$ of a $0.1 \%$ solution of indigo carmine was sprayed onto the jejunal mucosa on withdrawal of the endoscope.
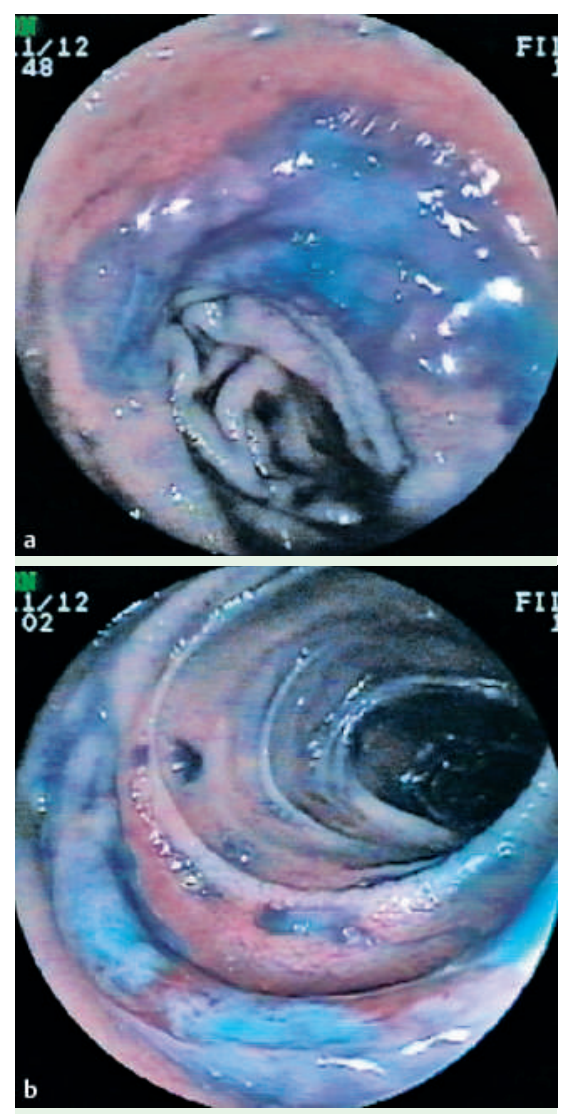

Figure 3 Chromoendoscopic views of circumferential jejunal ulcers in a patient with celiac disease which were proved histologically to contain enteropathy-associated T-cell lymphoma ( $0.1 \%$ indigo carmine dye) $(\mathbf{a}, \mathbf{b})$.

Scalloping or loss of folds, a mosaic appearance of the jejunal mucosa, and round or circumferential ulcers (10$90 \mathrm{~mm}$ along their longitudinal axis) were detected with standard video endoscopy, but the villi were easier to recognize after indigo carmine staining of scalloped jejunal folds ( $\bullet$ Figure 1 ) and ulcers were also highlighted ( Figure $\mathbf{2}$, - 3). Histological examination revealed the presence of enteropathy-associated T-cell lymphoma in biopsies taken from the ulcers and partial to subtotal villous atrophy in the nonulcerated mucosa. In comparison with standard endoscopy, indigo carmine chromoendoscopy highlighted areas of villous atrophy [4] and ul- 
cers, but did not add to the visual determination of other abnormalities such as scalloping, loss of folds, or the typical mosaic pattern [5]. The innovative doubleballoon endoscopy method is allowing the use of such techniques in deeply located lesions that are not usually accessible by standard endoscopy. Chromoendoscopy appears to be a suitable technique for examining suspicious areas during small-intestinal endoscopy.

Endoscopy_UCTN_Code_CCL_1AC_2AC
M. Hadithi, H. Akol, A. Al-Toma,

M. Jacobs, C. J. Mulder

Small Bowel Diseases Unit, Department of Gastroenterology, VU University Medical

Center, Amsterdam, The Netherlands

\section{References}

1 Mearin ML, Catassi C, Brousse N et al. European multi-centre study on coeliac disease and non-Hodgkin lymphoma. Eur J Gastroenterol Hepatol 2006; 18: 187- 194

2 Yoshida S, Yamaguchi H, Tajiri H et al. Diagnosis of early gastric cancer seen as less malignant endoscopically. Jpn J Clin Oncol 1984; 14: $225-241$

3 Kiesslich R, Mergener K, Naumann $C$ et al. Value of chromoendoscopy and magnification endoscopy in the evaluation of duodenal abnormalities: a prospective, randomized comparison. Endoscopy 2003; 35 : $559-563$
4 Lee SK, Green PH. Endoscopy in celiac disease. Curr Opin Gastroenterol 2005; 21: 589-594

5 Niveloni S, Fiorini A, Dezi R et al. Usefulness of videoduodenoscopy and vital dye staining as indicators of mucosal atrophy of celiac disease: assessment of interobserver agreement. Gastrointest Endosc 1998; 47: $223-229$

Bibliography

DOI 10.1055/s-2007-966315

Endoscopy 2007; 39: E212-E213

(C) Georg Thieme Verlag KG Stuttgart · New York . ISSN 0013-726X

Corresponding author

\section{Hadithi, MD}

Department of Gastroenterology

Groene Hart Ziekenhuis

P.O. Box 1098

2800 BB Gouda

The Netherlands

Fax: +31-182-505578

muhammed.hadithi@ghz.nl 